CLINICAL STUDY

\title{
Hypothalamic obesity: prevalence, associations and longitudinal trends in weight in a specialist adult neuroendocrine clinic
}

\author{
Caroline A Steele, Daniel J Cuthbertson, Ian A MacFarlane, Mohsen Javadpour ${ }^{1}$, Kumar S V Das ${ }^{2}$, \\ Catherine Gilkes ${ }^{1}$, John P Wilding and Christina Daousi \\ Department of Obesity and Endocrinology, University of Liverpool, Liverpool, UK and Departments of ${ }^{1}$ Neurosurgery and ${ }^{2}$ Neuroradiology, The Walton \\ Centre for Neurology and Neurosurgery, Liverpool, UK
}

(Correspondence should be addressed to C Daousi who is now at Obesity and Endocrinology Clinical Research Group, University Hospital Aintree, Clinical Sciences Centre, University of Liverpool, Lower Lane, LiverpoolL9 7AL, UK; Email: cdaousi@liverpool.ac.uk)

\begin{abstract}
Objective: Obesity is highly prevalent among adults with acquired, structural hypothalamic damage. We aimed to determine hormonal and neuroanatomical variables associated with weight gain and obesity in patients following hypothalamic damage and to evaluate the impact of early instigation of weight loss measures to prevent or limit the severity of obesity in these patients.

Design: Retrospective study of 110 adults with hypothalamic tumours attending a specialist neuroendocrine clinic. BMI was calculated at diagnosis and at last follow-up clinic visit. Endocrine data, procedures, treatments and weight loss measures were recorded and all available brain imaging reviewed.

Results: At last follow-up, 82.7\% of patients were overweight or heavier (BMI $\geq 25 \mathrm{~kg} / \mathrm{m}^{2}$ ), $57.2 \%$ were obese $\left(\mathrm{BMI} \geq 30 \mathrm{~kg} / \mathrm{m}^{2}\right)$ and $14.5 \%$ were morbidly obese $\left(\mathrm{BMI} \geq 40 \mathrm{~kg} / \mathrm{m}^{2}\right)$. Multivariate analysis revealed that use of desmopressin (odds ratio $(\mathrm{OR})=3.5 ; P=0.026), \mathrm{GH}(\mathrm{OR}=2.7 ; P=0.031)$ and thyroxine $(\mathrm{OR}=3.0 ; P=0.03)$ was associated with development of new or worsened obesity. Neuroimaging features were not associated with weight gain. Despite proactive treatments offered in clinic in recent years (counselling, dietetic and physical activity advice, and anti-obesity medications), patients have continued to gain weight.

Conclusions: Despite increased awareness, hypothalamic obesity is difficult to prevent and to treat. Improved understanding of the underlying pathophysiologies and multicentre collaboration to examine efficacy of novel obesity interventions are warranted.

European Journal of Endocrinology 168 501-507
\end{abstract}

\section{Introduction}

The hypothalamus is known to be a vital regulator of weight equilibrium by balancing energy intake with energy expenditure and body fat stores. When the hypothalamus is damaged, a syndrome of intractable weight gain can ensue termed 'hypothalamic obesity' (HO), which has received increased attention in recent years (1). The most common causes of acquired hypothalamic damage are space-occupying lesions, such as craniopharyngiomas and pituitary macroadenomas, with suprasellar extension and invasion of the hypothalamic nuclei. Hypothalamic damage can be caused by the tumour itself, or by its subsequent treatment with surgery or radiotherapy (2).

We had previously shown that obesity is highly prevalent among adult patients with acquired, structural hypothalamic damage and awareness had been raised of this significant complication among clinicians (1). HO is associated with a number of adverse health consequences leading to increased morbidity and mortality, i.e. cardiovascular disease (CVD), type 2 diabetes mellitus (T2DM), sleep-disordered breathing, non-alcoholic fatty liver disease (NAFLD), reduction in functional capacity and impaired quality of life. With regard to cardiovascular risk factors, these are highly prevalent and often inadequately treated in adult patients with hypothalamic-pituitary disease (3). Aggressive treatment of these factors is essential to reduce mortality and morbidity from CVD in these patients (4).

Effective treatments for HO have not yet been developed or evaluated. Following the publication of our initial findings in 2005, we adopted a more proactive approach to the management of these patients at risk of severe $\mathrm{HO}$ and its complications, aiming to limit the severity of weight gain through the early provision of dietary and behavioural modification, counselling, encouragement of regular physical activity, use of anti-obesity medications and referral to multidisciplinary weight management services. 
This retrospective study had the following aims: i) to ascertain the prevalence of obesity in one of the largest cohorts of adult patients who have sustained hypothalamic damage and have been followed up in a single centre in the UK, ii) to help determine hormonal and neuroanatomical variables associated with the development of new or worsened obesity following hypothalamic damage and iii) to evaluate the impact of early instigation of weight loss measures in an attempt to help prevent the development of or limit the severity of $\mathrm{HO}$.

\section{Materials and methods}

\section{Patients}

A retrospective study was conducted on 110 adult patients with tumours involving the hypothalamicpituitary region. All patients were attending a regional joint surgical and neuroendocrine clinic at the Walton Centre for Neurology and Neurosurgery in Liverpool, UK. Permission from the Institution's Audit Department was obtained and data were retrieved from the medical case notes and electronic records. All patients had undergone treatment for hypothalamic tumours, or adjacent tumours directly compressing or invading the hypothalamus. Fifty-three patients $(48.2 \%)$ had pituitary macroadenomas and hypothalamic invasion, 38 patients $(34.5 \%)$ had craniopharyngiomas and 19 patients $(17.3 \%)$ had other hypothalamic lesions (hypothalamic hamartomas, gliomas and histiocytosis X). The data described here represent clinical data from 2010 to early 2011. Treatment modalities including neurosurgical procedure(s) (transsphenoidal surgery or craniotomy), need for insertion of a ventricular drainage device and administration of conventional fractionated radiotherapy were recorded.

\section{Assessments}

Patients' height and weight at the time of diagnosis of their tumour were recorded where available. BMI $\left(\mathrm{kg} / \mathrm{m}^{2}\right)$ was calculated at diagnosis and at the last follow-up clinic visit. Changes in BMI were determined to identify the development of new or worsened obesity (defined as a BMI $\geq 30 \mathrm{~kg} / \mathrm{m}^{2}$ at last follow-up clinic visit, which had also increased by at least $2 \mathrm{~kg} / \mathrm{m}^{2}$ since the diagnosis of the tumour) (1). The glucagon stimulation test was used to assess ACTH and GH reserve. All patients with an inadequate cortisol response to glucagon underwent standard dose $(250 \mu \mathrm{g})$ short synacthen testing to confirm cortisol deficiency. Basal morning levels of TSH, free thyroxine, free triiodothyronine, prolactin, oestradiol, testosterone, cortisol and insulin-like growth factor 1 were also used to assess endocrine status as described previously (1). All available pre- and post-operative computed tomography (CT) and magnetic resonance imaging (MRI) scans for each patient were reviewed and scored by the same radiologist who was blind to the clinical data. The following anatomic features were recorded pre- and postoperatively: primary site of tumour; maximum extent $(\mathrm{mm})$ of the tumour from the midline (to the right and left) on coronal views; presence of suprasellar extension of pituitary tumours; encroachment of pituitary tumours on the optic chiasm; invasion or compression by extrahypothalamic tumours of adjacent hypothalamic tissue; distortion of the third ventricle on coronal images at the level of the infundibulum; any abnormalities of the floor of the third ventricle (partial or complete deficiency of the floor of the third ventricle) or breach of the tuber cinereum by the tumour and infiltration by the tumour of other brain areas, including the thalamus and temporal lobes. An MRI-based score of hypothalamic damage was produced for each patient based on the grading system previously described by Sainte-Rose.

\section{Statistical analysis}

The Wilcoxon signed-rank test was used to compare longitudinal changes in BMI in the 77 patients in whom serial data were available. Multiple logistic regression analysis was used to identify features associated with weight gain. Variables that differed significantly in the univariate analysis for patients with new or worsened obesity at latest follow-up were entered into the model. Statistical significance was defined as $P<0.05$ (two-tailed). All analyses were performed using SPSS, version 18.0.

\section{Results}

\section{Prevalence of obesity}

The entire cohort consists of 110 patients, with a median age of 55.5 years and a mean ( \pm s.D.) BMI of 33.7 ( \pm 7.5 , range $19-60) \mathrm{kg} / \mathrm{m}^{2}$. At last follow-up, 91 patients $(82.7 \%)$ were overweight or heavier $\left(\mathrm{BMI} \geq 25 \mathrm{~kg} / \mathrm{m}^{2}\right)$, $63(57.2 \%)$ were obese (BMI $\left.\geq 30 \mathrm{~kg} / \mathrm{m}^{2}\right)$ and $37(33.6 \%)$ had a $\mathrm{BMI} \geq 35 \mathrm{~kg} / \mathrm{m}^{2} ; 16(14.5 \%)$ patients were morbidly obese (BMI $\geq 40 \mathrm{~kg} / \mathrm{m}^{2}$ ). In comparison, in the general population of a similar age (aged 55-64 years), mean BMI is $28.2 \mathrm{~kg} / \mathrm{m}^{2}, 73.5 \%$ are overweight or heavier $\left(\mathrm{BMI} \geq 25 \mathrm{~kg} / \mathrm{m}^{2}\right)$ and $31 \%$ are obese $\left(\mathrm{BMI} \geq 30 \mathrm{~kg} / \mathrm{m}^{2}\right)$ (Health Survey for England 2007, The NHS Information Centre) (5). The prevalence of obesity in our population of patients with hypothalamic damage is nearly double that seen in the general background population. At their last clinic visit, 103/110 (94\%) patients were receiving replacement therapy with one or more pituitary hormone replacements, including 30 $(27 \%)$ who were receiving desmopressin for cranial diabetes insipidus. 
Table 1 Characteristics of the patients with serial data $(n=77)$ according to obesity status.

\begin{tabular}{lllc}
\hline & \multicolumn{2}{c}{ Number $(\%)$ or mean \pm s.D. } & \\
\cline { 2 - 4 } Characteristic & $\begin{array}{l}\text { New or worsened } \\
\text { obesity }(n=42)\end{array}$ & $\begin{array}{l}\text { No weight } \\
\text { gain }(n=35)\end{array}$ & P value \\
\hline Current age (years) & $55.7 \pm 13.1$ & $54.2 \pm 17.7$ & 0.9 \\
Age at diagnosis (years) & $43.4 \pm 15.7$ & $44.5 \pm 17.7$ & 0.4 \\
Male sex & $22(52.4)$ & $21(60)$ & 0.4 \\
Years of follow-up & $10.8 \pm 6.8$ & $8.5 \pm 5.9$ & 0.6 \\
Baseline BMI $\left(\mathrm{kg} / \mathrm{m}^{2}\right)$ & $30.9 \pm 6.8$ & $26.2 \pm 4.8$ & 0.001 \\
Current BMI $\left(\mathrm{kg} / \mathrm{m}^{2}\right)$ & $38.6 \pm 7.2$ & $27.4 \pm 3.6$ & $<0.0001$ \\
Transsphenoidal surgery & $18(43)$ & $22(63)$ & 0.2 \\
Craniotomy & $21(50)$ & $10(29)$ & 0.07 \\
Radiotherapy & $26(62)$ & $18(51)$ & 0.4 \\
Ventriculoperitoneal shunt & $7(17)$ & $4(11)$ & 0.5 \\
Hydrocortisone replacement & $34(81)$ & $23(66)$ & 0.2 \\
Hydrocortisone dose (mg) & $22.3 \pm 5.3$ & $25.7 \pm 6.2$ & 0.04 \\
GH replacement & $29(69)$ & $14(40)$ & 0.007 \\
Thyroxine replacement & $35(83)$ & $18(51)$ & 0.008 \\
Sex steroids & $27(64)$ & $16(46)$ & 0.9 \\
Desmopressin & $15(36)$ & $2(17)$ & 0.02 \\
Invasion of thalamus on MRI & $1(2)$ & $4(6)$ & 0.5 \\
Invasion of temporal lobe on MRI & $6(14)$ & $14(40)$ & 0.5 \\
Abnormalities of third ventricle & $15(36)$ & & 0.9 \\
\hline
\end{tabular}

MRI, magnetic resonance imaging.

\section{Treatments for obesity}

Seventeen patients from the entire cohort have received treatment with orlistat in recent years and four patients had received multiple weight loss medications (orlistat, sibutramine and rimonabant, the latter two before their withdrawal from the market due to safety concerns). Six patients at their last clinic follow-up were attending a hospital-based multi-professional weight management clinic, all of whom were seen regularly by a dietician and a physician with a special interest in weight management. None of the patients in our cohort had undergone bariatric surgery.

\section{Longitudinal changes in weight and BMI}

At the time of diagnosis and treatment of their tumour, height and weight measurements were available for 77 out of the 110 patients. Their mean $( \pm$ s.D. $)$ age at last clinic assessment was $44 \pm 16.5$ years. There was a highly significant increase in median BMI, from $28.1 \mathrm{~kg} / \mathrm{m}^{2}$ at baseline (interquartile range (IQR), $24.3-32.4 \mathrm{~kg} / \mathrm{m}^{2}$ ) to $32 \mathrm{~kg} / \mathrm{m}^{2}$ (IQR, $\left.27.7-38.38 \mathrm{~kg} / \mathrm{m}^{2}\right)$ at the last followup $(P<0.0001)$, a median of 9 years after diagnosis of their tumour. Weight gain was fastest within the first year after diagnosis of their tumour, with an increase in mean BMI to $30.4 \mathrm{~kg} / \mathrm{m}^{2}(P<0.0001)$; the rate of weight gain subsequently declined but did not plateau.

\section{Variables associated with obesity and weight gain since diagnosis}

Patients with new or worsened obesity at last clinic follow-up were more likely to be receiving $\mathrm{GH}$ replacement therapy $(P=0.007)$, thyroxine $(P=0.008)$ or desmopressin $(P=0.02)$. Multivariate analysis revealed that use of desmopressin (odds ratio $(\mathrm{OR})=$ 3.5; $95 \%$ CI: 1.2 to $10.8 ; P=0.026)$, $\mathrm{GH}(\mathrm{OR}=2.7$; $95 \%$ CI: 1.1 to $6.9 ; P=0.031)$ and thyroxine $(\mathrm{OR}=3.0$; 95\% CI: 1.1 to $8.0 ; P=0.03)$ was associated with the development of new or worsened obesity. A number of neuroradiological features examined on preoperative CT/MRIs and post-operative neuroimaging and the original histological diagnosis were not associated with weight gain and patients' obesity status at last clinic assessment (Table 1). The degree of hypothalamic damage as assessed by the MRI-based score using the Sainte-Rose grading system (grade 1 and grade 2 hypothalamic damage) did not impact on the risk of development of new or worsened obesity. Similarly, treatment modalities with a greater theoretical likelihood of causing hypothalamic damage, such as craniotomy or radiotherapy, were not associated with increased weight gain following diagnosis.

\section{Patients diagnosed with hypothalamic tumours between 2005 and 2011}

Since the publication of our findings in 2005 of high prevalence of obesity among patients with acquired hypothalamic damage, 35 new patients with hypothalamic tumours have been diagnosed and treated at our centre. The mean ( \pm s.D. $)$ age of these 35 patients at diagnosis was $50.9 \pm 15.6$ years and $23(66 \%)$ were men. After a median period of follow-up of 3 years, there has been an increase in median BMI from $29.9 \mathrm{~kg} / \mathrm{m}^{2}$ (IQR, $26.5-33.4 \mathrm{~kg} / \mathrm{m}^{2}$ ) at baseline to $31.7 \mathrm{~kg} / \mathrm{m}^{2}$ (IQR, $27.8-38.8 \mathrm{~kg} / \mathrm{m}^{2}$ ) at last clinic follow-up $(P<0.001)$ (Fig. 1). Despite the increase in awareness 


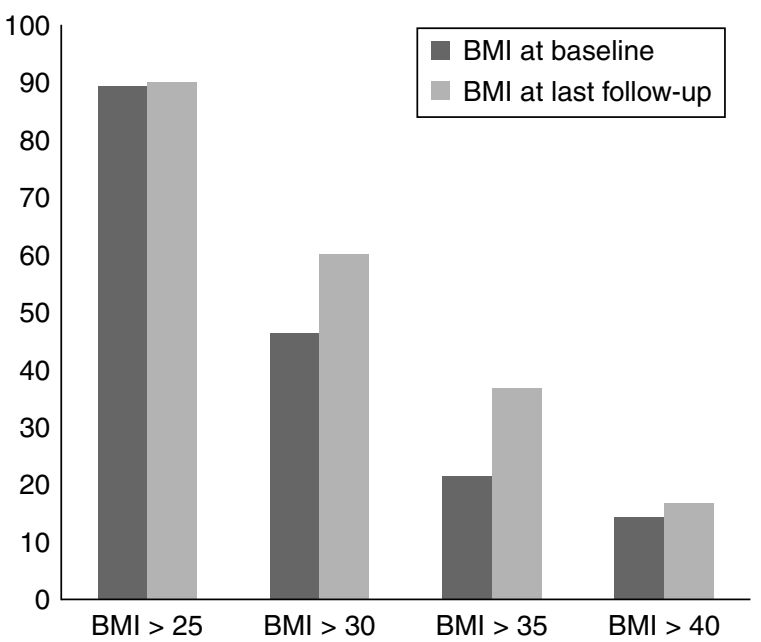

Figure 1 Prevalence of obesity in new patients diagnosed and treated for a hypothalamic tumour during the period 2005-2011 $(n=35)$. BMl calculated as $\mathrm{kg} / \mathrm{m}^{2}$.

and proactive treatments offered in our clinic since the dissemination of our findings in 2005, newly diagnosed patients have continued to gain weight. All these patients were adequately hormonally replaced where necessary and all had received counselling about their weight, dietetic advice and encouragement for regular physical activity if other co-morbidities permitted. Five of the patients had been treated with anti-obesity medications (four treated with orlistat and one with orlistat followed by sibutramine) and one patient was attending a hospital-based multi-professional weight management clinic.

\section{Discussion}

This is the largest ever study examining BMI trends and weight gain patterns in adult patients with acquired structural hypothalamic damage. Our current findings of a continuing increase in the prevalence and severity of obesity in these patients reflect the difficulty in both preventing and treating obesity secondary to hypothalamic damage. These body weight changes occurred despite increased awareness of the problem in our clinic population (1) and early instigation of measures such as dietary advice, professional dietetic input, recommendation of regular physical activity and, where considered clinically appropriate, drug therapy to support weight loss.

The increased prevalence of cardiovascular risk factors and the metabolic syndrome, well documented in patients with hypothalamic-pituitary disease (3) and craniopharyngioma $(6,7)$, are also particularly common in those with hypothalamic damage that has occurred at a relatively young age (8) despite adequate pituitary hormone replacement (8). Obesity is associated with numerous co-morbidities such as CVD, T2DM, hypertension, NAFLD, certain cancers and sleep apnoea. In fact, obesity is an independent risk factor for CVD (9). These observations combined highlight the importance of the high prevalence of obesity in a population with an already increased CVD background.

Our current data confirm our previous findings from a smaller cohort of patients (1) that pre- and postoperative MRI in adult patients with hypothalamic damage cannot predict patients at high risk of postoperative weight gain. Other groups have described a correlation between MRI findings and the risk of $\mathrm{HO}$ in children with craniopharyngiomas $(10,11)$. The extent of involvement of the hypothalamus on preoperative MRI has been used by others to help guide treatment in terms of extent of resection of craniopharyngioma (12), where preservation of the hypothalamus is advocated rather than complete (total) surgical resection, in those without hypothalamic involvement. A recent paper by Van Gompel et al. (13) of 28 adult patients with craniopharyngioma undergoing surgery found that a worse preoperative MRI score, using a scale described by Sainte-Rose et al. (14), was associated with an increased risk of post-operative weight gain. However, they limited the follow-up to a maximum of 2 years and no patients in their study were treated with $\mathrm{GH}$, and it remains unclear how many of their patients had symptomatic severe GH deficiency that would have warranted replacement (13). These factors and their limitation to patients with craniopharyngioma only may explain the differences from our findings.

Multivariate analysis revealed that $\mathrm{GH}$, levothyroxine and desmopressin replacement were associated with development of new or worsened obesity and the requirement for multiple endocrine replacements may reflect the extent of hypothalamic damage, such as bilateral damage to the paraventricular and supraoptic nuclei in patients with permanent central diabetes insipidus. The paraventricular nucleus, apart from its role in vasopressin release, is also an important part of the neuroendocrine circuitry that controls energy balance. These circuits would be unlikely to remain completely intact following a hypothalamic insult that also leads to cranial diabetes insipidus.

There are multiple different theories as to the pathophysiology underlying weight gain and obesity in those with acquired structural hypothalamic damage. A few of the proposed pathophysiological mechanisms are: hyperphagia and increased energy intake; hyperinsulinism due to autonomic nervous system dysregulation, leptin resistance, reduced physical activity and reduced basal metabolic rate; melatonin dysregulation and enhanced 11- $\beta$ hydroxysteroid dehydrogenase-1 activity $(15,16,17,18)$. It seems likely that, as the hypothalamus is responsible for both integrating and initiating multiple pathways influencing body weight, any or several of these mechanisms may be responsible and that this may vary between individual patients $(15,19,20)$. 
Treatment of simple obesity is extremely challenging; however, HO is even more refractory to conventional therapeutic interventions. Given the multiple underlying pathophysiological pathways, which may become disturbed and contribute towards $\mathrm{HO}$, it is not surprising that no single effective treatment has been developed and successfully applied. A variety of pharmacological approaches have been tried over the years, targeting a number of different putative pathophysiological mechanisms underlying HO. One such approach aimed at lowering insulin levels that have previously been demonstrated to be elevated in children with $\mathrm{HO}$ $(21,22)$. An open-label and a double-blind, placebocontrolled trial with the somatostatin agonist octreotide in children with $\mathrm{HO}$ has demonstrated weight loss and weight stabilisation along with reductions in insulin levels $(21,22)$. There is limited evidence for the use of sibutramine $(23,24)$, dextroamphetamine $(25,26)$, metformin (27), GLP-1 receptor agonists (28), supraphysiological doses of $\mathrm{T}_{3}$ (29) and melatonin (30) as treatments in $\mathrm{HO}$ in both children and adults. No studies of orlistat in the HO population exist; however, its use has been mentioned in only a few case reports. We have used orlistat in a small number of our patients $(n=17)$, with variable results. A small number of reports have been published describing the use of bariatric surgery in patients with HO showing significant weight loss and weight loss maintenance $(31,32$, 33, 34).

Based on our collective experience from our clinic population of adults with hypothalamic tumours, we would recommend regular weight measurements to be undertaken at every clinic visit. After ensuring adequate replacement (without over-replacement) of all pituitary hormone deficits, it is important to consider dietary and exercise advice as first-line measures and counselling of the patient regarding the increased risk of weight gain especially within the first year following treatment of their hypothalamic tumour. Lifestyle programmes alone are unlikely to be sufficient and there are no studies that conclusively demonstrate the effectiveness of physical activity in patients with HO. Drug therapy is often needed in addition, and as in simple obesity, it is of variable success. Referral to a multi-disciplinary weight management service (where available) should also be considered, but patients should be warned that their weight gain may be difficult to treat despite in some cases no evidence of inappropriate diet or sedentary lifestyle. It is important to emphasise to the patients, however, that while their weight gain and obesity may be more refractory to the usual diet and exercise advice, there are currently limited treatment options available and therefore it is even more important to ensure that these aspects are addressed adequately. Stabilisation of weight, after years of incessant weight gain, is as much of an achievement as weight loss in these patients. Questioning regarding complications of obesity, such as development of T2DM, NAFLD or sleep apnoea, with referral for further specialist assessment, is also important.

To further investigate the underlying pathophysiologies involved in weight gain following hypothalamic damage, non-invasive modalities such as functional neuroimaging (positron emission tomography and functional MRI) may provide useful insights, as it has in those with simple obesity. Functional neuroimaging has helped to identify neuroanatomical correlates of hunger, satiety and feeding and has demonstrated how the brain is affected under different experimental conditions $(35,36,37,38)$, after presentation of food images (with differences between high-calorie, lowcalorie and neutral picture stimuli) $(37,39)$ and has demonstrated differences between obese and lean individuals $(36,37,40)$. Functional neuroimaging studies in patients with HO may help shed light on the underlying pathophysiology.

Engagement and compliance with the weight management treatments offered in our study were excellent and all participants were highly motivated and keen to avoid further weight gain or to achieve clinically meaningful weight loss. Caution should be exercised when interpreting the response to these weight loss interventions as the number of patients studied was small. As HO is a relatively rare condition with little awareness from the medical and surgical communities, multicentre collaboration involving specialist centres for further research, including perhaps multi-drug trials and ideally randomised trials of intensive lifestyle interventions vs routine care, would be beneficial to patients and clinicians.

\section{Declaration of interest}

C Daousi, D J Cuthbertson and J P Wilding have received research grants from Merck Sharpe \& Dohme (MSD), Eli Lilly and the NovoNordisk UK Research Foundation. J P Wilding has received consulting and speaker fees from MSD, NovoNordisk, Astra Zeneca and Eli Lilly. C Daousi, I A MacFarlane and D J Cuthbertson have received research grant support from Otsuka, Lilly, Ipsen and Pfizer. C A Steele, K S V Das, C Gilkes and M Javadpour have nothing to disclose.

\section{Funding}

This research did not receive any specific grant from any funding agency in the public, commercial or not-for-profit sector.

\section{References}

1 Daousi C, Dunn AJ, Foy PM, MacFarlane IA \& Pinkney JH. Endocrine and neuroanatomic features associated with weight gain and obesity in adult patients with hypothalamic damage. American Journal of Medicine 2005118 45-50. (doi:10.1016/ j.amjmed.2004.06.035)

2 Daousi C, MacFarlane IA, English PJ, Wilding JP, Patterson M, Dovey TM, Halford JC, Ghatei MA \& Pinkney JH. Is there a role for ghrelin and peptide-YY in the pathogenesis of obesity in adults with acquired structural hypothalamic damage? Journal of Clinical Endocrinology and Metabolism 200590 5025-5030. (doi:10.1210/jc.2004-1874) 
3 Deepak D, Furlong NJ, Wilding JP \& MacFarlane IA. Cardiovascular disease, hypertension, dyslipidaemia and obesity in patients with hypothalamic-pituitary disease. Postgraduate Medical Journal 200783 277-280. (doi:10.1136/pgmj.2006.052241)

4 Tomlinson JW, Holden N, Hills RK, Wheatley K, Clayton RN, Bates AS, Sheppard MC \& Stewart PM. Association between premature mortality and hypopituitarism. West Midlands Prospective Hypopituitary Study Group. Lancet 2001357 425-431. (doi:10.1016/S0140-6736(00)04006-X)

5 Department of Health: Health Survey for England. Body Mass Index (BMI), by survey year, age and sex. Available at: http://www. doh.gov.uk/stats/tables/trendtab.xls. Accessed August, 2012.

6 Bulow B, Attewell R, Hagmar L, Malmstrom P, Nordstrom CH \& Erfurth EM. Postoperative prognosis in craniopharyngioma with respect to cardiovascular mortality, survival, and tumor recurrence. Journal of Clinical Endocrinology and Metabolism $1998 \mathbf{8 3}$ 3897-3904. (doi:10.1210/jc.83.11.3897)

7 Srinivasan S, Ogle GD, Garnett SP, Briody JN, Lee JW \& Cowell CT. Features of the metabolic syndrome after childhood craniopharyngioma. Journal of Clinical Endocrinology and Metabolism $2004 \mathbf{8 9}$ 81-86. (doi:10.1210/jc.2003-030442)

8 Holmer H, Ekman B, Björk J, Nordstöm CH, Popovic V, Siversson A \& Erfurth EM. Hypothalamic involvement predicts cardiovascular risk in adults with childhood onset craniopharyngioma on longterm GH therapy. European Journal of Endocrinology 2009161 671-679. (doi:10.1530/EJE-09-0449)

9 Poirier P, Giles TD, Bray GA, Hong Y, Stern JS, Pi-Sunyer FX, Eckel RH \& American Heart Association; Obesity Committee of the Council on Nutrition, Physical Activity, and Metabolism. Obesity and cardiovascular disease: pathophysiology, evaluation, and effect of weight loss: an update of the 1997 American Heart Association Scientific Statement on Obesity and Heart Disease from the Obesity Committee of the Council on Nutrition, Physical Activity, and Metabolism. Circulation 2006113 898-918. (doi:10.1161/CIRCULATIONAHA.106.171016)

10 De Vile CJ, Grant DB, Hayward RD, Kendall BE, Neville BG \& Stanhope R. Obesity in childhood craniopharyngioma: relation to post-operative hypothalamic damage shown by magnetic resonance imaging. Journal of Clinical Endocrinology and Metabolism 199681 2734-2737. (doi:10.1210/jc.81.7.2734)

11 Meuric S, Brauner R, Trivin C, Souberbielle JC, Zerah M \& SainteRose C. Influence of tumor location on the presentation and evolution of craniopharyngiomas. Journal of Neurosurgery 2005 $103421-426$.

12 Puget S, Garnett M, Wray A, Grill J, Habrand JL, Bodaert N, Zerah M, Bezerra M, Renier D, Pierre-Kahn A et al. Pediatric craniopharyngiomas: classification and treatment according to the degree of hypothalamic involvement. Journal of Neurosurgery $20071063-12$

13 Van Gompel JJ, Nippoldt TB, Higgins DM \& Meyer FB. Magnetic resonance imaging-graded hypothalamic compression in surgically treated adult craniopharyngiomas determining postoperative obesity. Neurosurgical Focus 201028 E3. (doi:10.3171/2010.1. FOCUS09303)

14 Sainte-Rose C, Puget S, Wray A, Zerah M, Grill J, Brauner R, Boddaert N \& Pierre-Kahn A. Craniopharyngioma: the pendulum of surgical management. Child's Nervous System 200521 691-695. (doi:10.1007/s00381-005-1209-2)

15 Lee M \& Korner J. Review of physiology, clinical manifestations, and management of hypothalamic obesity in humans. Pituitary 200912 87-95. (doi:10.1007/s11102-008-0096-4)

16 Muller HL. Consequences of craniopharyngioma surgery in children. Journal of Clinical Endocrinology and Metabolism 2011 96 1981-1991. (doi:10.1210/jc.2011-0174)

17 Roth CL, Gebhardt U \& Muller HL. Appetite-regulating hormone changes in patients with craniopharyngioma. Obesity 201119 36-42. (doi:10.1038/oby.2010.80)

18 Lustig RH. Hypothalamic obesity: causes, consequences, treatment. Pediatric Endocrinology Reviews 20086 220-227.
19 Pinkney J, Wilding J, Williams G \& MacFarlane I. Hypothalamic obesity in humans: what do we know and what can be done? Obesity Reviews 20023 27-34. (doi:10.1046/j.1467-789X.2002. 00052.x)

20 Hochberg I \& Hochberg Z. Expanding the definition of hypothalamic obesity. Obesity Reviews $2010 \quad 11 \quad 709-721$. (doi:10.1111/j.1467-789X.2010.00727.x)

21 Lustig RH, Rose SR, Burghen GA, Velasquez-Mieyer P, Broome DC, Smith K, Li H, Hudson MM, Heideman RL \& Kun LE. Hypothalamic obesity caused by cranial insult in children: altered glucose and insulin dynamics and reversal by a somatostatin agonist. Journal of Pediatrics 1999135 162-168. (doi:10.1016/ SO022-3476(99)70017-X)

22 Lustig RH, Hinds PS, Ringwald-Smith K, Christensen RK, Kaste SC, Schreiber RE, Rai SN, Lensing SY, Wu S \& Xiong X. Octreotide therapy of pediatric hypothalamic obesity: a doubleblind, placebo-controlled trial. Journal of Clinical Endocrinology and Metabolism 200388 2586-2592. (doi:10.1210/jc.2002030003)

23 Arango C, Rojas MJ, Moreno D \& Parellada M. Sibutramine for compulsive eating in hypothalamic deficiency. Journal of the American Academy of Child and Adolescent Psychiatry $2002 \mathbf{4 1}$ 1147-1148. (doi:10.1097/00004583-200210000-00004)

24 Danielsson P, Janson A, Norgren S \& Marcus C. Impact sibutramine therapy in children with hypothalamic obesity or obesity with aggravating syndromes. Journal of Clinical Endocrinology and Metabolism 200792 4101-4106. (doi:10.1210/jc. 2007-0826)

25 Mason PW, Krawiecki N \& Meacham LR. The use of dextroamphetamine to treat obesity and hyperphagia in children treated for craniopharyngioma. Archives of Pediatrics $\mathcal{E}$ Adolescent Medicine $2002156887-892$.

26 Ismail D, O'Connell MA \& Zacharin MR. Dexamphetamine use for management of obesity and hypersomnolence following hypothalamic injury. Journal of Pediatric Endocrinology \& Metabolism $200619129-134$.

27 Igaki N, Tanaka M \& Goto T. Markedly improved glycemic control and enhanced insulin sensitivity in a patient with type 2 diabetes complicated by a suprasellar tumor treated with pioglitazone and metformin. Internal Medicine 200544 832-837. (doi:10.2169/ internalmedicine.44.832)

28 Thondam SK, Cuthbertson DJ, Aditya BS, MacFarlane IA, Wilding JP \& Daousi C. A glucagon-like peptide-1 (GLP-1) receptor agonist in the treatment of hypothalamic obesity complicated by type 2 diabetes mellitus. Clinical Endocrinology 201277 635-637. (doi:10.1111/j.1365-2265.2012.04368.x)

29 Fernandes JK, Klein MJ, Ater JL, Kuttesch JF \& VassilopoulouSellin R. Triiodothyronine supplementation for hypothalamic obesity. Metabolism 200251 1381-1383. (doi:10.1053/meta. 2002.35591)

30 Müller HL, Handwerker G, Gebhardt U, Faldum A, Emser A, Kolb R \& Sörensen N. Melatonin treatment in obese patients with childhood craniopharyngioma and increased daytime sleepiness. Cancer Causes \& Control 200617 583-589. (doi:10.1007/ s10552-005-9012-7)

31 Müller HL, Gebhardt U, Wessel V, Schröder S, Kolb R, Sörensen N, Maroske J \& Hanisch E. First experiences with laparoscopic adjustable gastric banding (LAGB) in the treatment of patients with childhood craniopharyngioma and morbid obesity. Klinische Padiatrie 2007219 323-325. (doi:10.1055/s-2007985848)

32 Inge TH, Pfluger P, Zeller M, Rose SR, Burget L, Sundararajan S, Daniels SR \& Tschöp MH. Gastric bypass surgery for treatment of hypothalamic obesity after craniopharyngioma therapy. Nature Clinical Practice. Endocrinology \& Metabolism 20073 606-609. (doi:10.1038/ncpendmet0579)

33 Schultes B, Ernst B, Schmid F \& Thurnheer M. Distal gastric bypass surgery for the treatment of hypothalamic obesity after childhood craniopharyngioma. European Journal of Endocrinology 2009161 201-206. (doi:10.1530/EJE-09-0079) 
34 Rottembourg D, O'Gorman CS, Urbach S, Garneau PY, Langer JC, Van Vliet G, Hamilton J \& Huot C. Outcome after bariatric surgery in two adolescents with hypothalamic obesity following treatment of craniopharyngioma. Journal of Pediatric Endocrinology $\mathcal{E}$ Metabolism 200922 867-872.

35 Tataranni PA, Gautier JF, Chen K, Uecker A, Bandy D, Salbe AD, Pratley RE, Lawson M, Reiman EM \& Ravussin E. Neuroanatomical correlates of hunger and satiation in humans using positron emission tomography. PNAS 199996 4569-4574. (doi:10.1073/ pnas.96.8.4569)

36 Gautier JF, Del Parigi A, Chen K, Salbe AD, Bandy D, Pratley RE, Ravussin E, Reiman EM \& Tataranni PA. Effect of satiation on brain activity in obese and lean women. Obesity Research 20019 676-684. (doi:10.1038/oby.2001.92)

37 Killgore WD, Young AD, Femia LA, Bogorodzki P, Rogowska J \& Yurgelun-Todd DA. Cortical and limbic activation during viewing of high- versus low-calorie foods. NeuroImage 200319 1381-1394. (doi:10.1016/S1053-8119(03)00191-5)
38 Smeets PA, de Graaf C, Stafleu A, van Osch MJ, Nievelstein RA \& van der Grond J. Effect of satiety on brain activation during chocolate tasting in men and women. American Journal of Clinical Nutrition 200683 1297-1305.

39 Schur EA, Kleinhans NM, Goldberg J, Buchwald D, Schwartz MW \& Maravilla K. Activation in brain energy regulation and reward centers by food cues varies with choice of visual stimulus. International Journal of Obesity 200933 653-661. (doi:10.1038/ ijo.2009.56)

40 Gautier JF, Chen K, Salbe AD, Bandy D, Pratley RE, Heiman M, Ravussin E, Reiman EM \& Tataranni PA. Differential brain responses to satiation in obese and lean men. Diabetes 200049 838-846. (doi:10.2337/diabetes.49.5.838)

Received 9 September 2012

Revised version received 16 December 2012

Accepted 3 January 2013 